OPEN ACCESS

Edited by:

Karine Rachel Prudent Breckpot, Vrije University Brussel, Belgium

Reviewed by: Andrea Riccardo Filippi, University of Pavia, Italy Cleo Goyvaerts, Vrije University Brussel, Belgium Jun-Ling Li,

Chinese Academy of Medical Sciences and Peking Union Medical College, China

*Correspondence: Hiva Mamdan mamdanih@karmanos.org

Specialty section:

This article was submitted to Cancer Immunity and Immunotherapy, a section of the journal

Frontiers in Immunology

Received: 27 November 2021 Accepted: 20 January 2022 Published: 09 February 2022

Citation:

Mamdani H, Matosevic S, Khalid AB, Durm G and Jalal SI (2022) Immunotherapy in Lung

Cancer: Current Landscape and Future Directions.

Front. Immunol. 13:823618. doi: 10.3389/fimmu.2022.823618

\section{Immunotherapy in Lung Cancer: Current Landscape and Future Directions}

\author{
Hirva Mamdani ${ }^{1 *}$, Sandro Matosevic ${ }^{2}$, Ahmed Bilal Khalid $^{3}$, Gregory Durm ${ }^{4}$ \\ and Shadia I. Jalal ${ }^{4}$ \\ 1 Department of Oncology, Barbara Ann Karmanos Cancer Institute, Wayne State University, Detroit, MI, United States, \\ 2 Department of Industrial and Physical Pharmacy, Purdue University, West Lafayette, IN, United States, ${ }^{3}$ Department of \\ Internal Medicine, Indiana University, Indianapolis, IN, United States, ${ }^{4}$ Department of Internal Medicine, Division of \\ Hematology/Oncology, Indiana University Melvin and Bren Simon Cancer Center, Indiana University School of Medicine, \\ Indianapolis, IN, United States
}

Over the past decade, lung cancer treatment has undergone a major paradigm shift. A greater understanding of lung cancer biology has led to the development of many effective targeted therapies as well as of immunotherapy. Immune checkpoint inhibitors (ICls) have shown tremendous benefit in the treatment of non-small cell lung cancer (NSCLC) and are now being used as first-line therapies in metastatic disease, consolidation therapy following chemoradiation in unresectable locally advanced disease, and adjuvant therapy following surgical resection and chemotherapy in resectable disease. Despite these benefits, predicting who will respond to ICls has proven to be difficult and there remains a need to discover new predictive immunotherapy biomarkers. Furthermore, resistance to ICls in lung cancer is frequent either because of a lack of response or disease progression after an initial response. The utility of ICls in the treatment of small cell lung cancer (SCLC) remains limited to first-line treatment of extensive stage disease in combination with chemotherapy with modest impact on overall survival. It is thus important to explore and exploit additional targets to reap the full benefits of immunotherapy in the treatment of lung cancer. Here, we will summarize the current state of immunotherapy in lung cancer, discuss novel targets, and explore the intersection between DNA repair defects and immunotherapy.

Keywords: immune checkpoint inhibitors, immunotherapy, lung cancer, engineered immune cells, cellular therapy, DNA repair

\section{INTRODUCTION}

Lung cancer is the number one cause of cancer related mortality. Over the last decade, a greater understanding of the biology of lung cancer at the molecular level has led to the development of new and effective therapies resulting in improvement in overall survival (OS), mostly driven by advances in the treatment of non-small cell lung cancer (NSCLC) (1). Traditionally, advanced NSCLC was thought to be one disease. More recently, it has been recognized that NSCLC is on a biological level a set of multiple diseases. Targeted treatments are standard of care in driver mutation positive NSCLC with 
numerous approved targeted therapies (2). In patients without a driver mutation, immunotherapy in the form of immune checkpoint inhibitor(s) (ICIs) is currently an integral part of the treatment (2). Programmed cell death ligand-1 (PD-L1) is one of the predictive biomarkers of response to checkpoint inhibitors. $\mathrm{PD}-\mathrm{L} 1$ expression is an imperfect biomarker but is the most robust clinical one. NSCLC, however, continues to have a high mortality rate. Most patients with advanced disease eventually progress on first-line treatment and second-line options are limited for patients without a targetable mutation. Moreover, the clinical application of ICI in the treatment of small cell lung cancer (SCLC) has significantly lagged behind that of NSCLC. There remains a critical need to further harness the power of the immune system, expand treatment options, and delay resistance to ICIs. In this article, we will discuss the current standard immunotherapy treatments and potential novel immunotherapy targets and approaches in lung cancer. We will, in addition, shed light on the interplay between DNA repair defects and immunotherapy, an area of great research interest.

\section{CURRENT ROLE OF IMMUNOTHERAPY IN LUNG CANCER}

The relentless nature of any cancer is often attributed to its vast mutational repertoire equipping the cancer cells with mechanisms to develop resistance to commonly used treatment strategies. It is not surprising that lung cancer, with its major histologic subtypes, is among the top five tumor types carrying the highest number of somatic mutations (3). In the first decade of $21^{\text {st }}$ century, median OS of patients diagnosed with advanced NSCLC and SCLC was one year. The discovery of actionable driver genomic alterations and development of targeted therapies led to striking improvement in OS of a subset of NSCLC patients. The survival of the vast majority of patients with NSCLC without an actionable genomic driver and virtually all patients with SCLC remained limited and platinum-based chemotherapy was the mainstay of first-line therapy for these patients.

The discovery of immune checkpoints and subsequent development of Nobel Prize winning ICIs have brought in a radical revolution in the therapeutic landscape of lung cancer, specifically $\operatorname{NSCLC}(4,5)$. Of the several known immune checkpoints utilized by the tumor to evade host immune system, the best known and farthest along in clinical application is programmed cell death protein-1/programmed cell death ligand-1(PD-1/PD-L1) and cytotoxic T lymphocyte antigen-4 (CTLA-4) pathways. Inhibition of these pathways enables priming and anti-tumor activity of cytotoxic T-cells, the essential steps that are otherwise inhibited by the expression of B7-1/2 and PD-L1 by the antigen presenting cells carrying tumor associated antigens and tumor cells, respectively (4).

The first breakthrough in the utility of ICIs in treatment of lung cancer was in the form of PD-1 inhibitor nivolumab as second-line therapy for patients with advanced NSCLC, when randomized phase III trials showed superior objective response rate (ORR) and OS with nivolumab compared to docetaxel in patients with advanced squamous and non-squamous NSCLC following progression on platinum-based chemotherapy $(6,7)$. Shortly thereafter, another PD-1 inhibitor pembrolizumab and PD-L1 inhibitor atezolizumab were approved by the US FDA for the same indication, based on superior efficacy of these agents compared to docetaxel in second-line setting $(8,9)$. The success of ICIs in second-line setting paved the way for their use in first-line treatment of advanced NSCLC. A plethora of phase III clinical trials reported over the past five years, showing durable responses and unprecedented improvement in OS with ICI or ICI plus platinumbased chemotherapy compared to chemotherapy alone, have rapidly expanded first-line treatment options for patients with advanced NSCLC not harboring sensitizing EGFR mutations or ALK translocations. These options include pembrolizumab, atezolizumab, cemiplimab, nivolumab plus CTLA-4 inhibitor ipilimumab, pembrolizumab plus platinum-based chemotherapy, atezolizumab plus platinum-based chemotherapy with or without bevacizumab (for non-squamous histology), and nivolumab plus ipilimumab plus two cycles of platinum-based chemotherapy (1017). The choice of therapy in clinical practice is largely determined by PD-L1 expression, burden of disease, and tumor mutation profile. Besides the improvement in response rates and OS, one of the most fascinating aspects of using ICI-based therapies in NSCLC is the durability of survival benefit. For example, recently reported 5-year outcomes of landmark KEYNOTE-024 trial comparing pembrolizumab with chemotherapy as first-line treatment for patients with advanced NSCLC harboring PD-L1 expression of $\geq 50 \%$ demonstrated unprecedented 5 -year OS of $32 \%$ with pembrolizumab (18). Randomized trials comparing nivolumab with docetaxel in second-line treatment of advanced NSCLC have also reported that a subset of patient derive prolonged and clinically meaningful survival benefit with ICI (19).

The success march of ICI in NSCLC has expanded to unresectable stage III and more recently to resectable stage IIIIIA disease. In a randomized phase III trial comparing PD-L1 inhibitor durvalumab with placebo in patients with unresectable stage III NSCLC who had non-progressive disease following concurrent chemoradiation, durvalumab showed superior progression free survival (PFS) and OS which were sustained at 5-year follow up, further affirming the durability of anti-tumor activity of ICI in NSCLC $(20,21)$. Another phase III trial comparing atezolizumab with best supportive care in patients with resectable stable IB-IIIA NSCLC following complete surgical resection and adjuvant platinum-based chemotherapy showed superior disease-free survival (DFS) with atezolizumab which led to recent FDA approval of the agent for adjuvant therapy for patients with resected stage II-IIIA disease with positive PD-L1 expression (22).

In contrast to the exponential growth of the ICI field in NSCLC, the success in SCLC remains disappointing. The only breakthrough in the treatment of extensive-stage SCLC over the past three decades has been the addition of PD-L1 inhibitors durvalumab or atezolizumab to platinum-based chemotherapy for first-line treatment. While the combination has now become the standard of care, the improvement in median OS with the addition of ICI to chemotherapy is modest at best $(23,24)$. 
The utility of ICI therapy, either concurrently or sequentially following chemoradiation, in patients with limited-stage SCLC is being evaluated in clinical trials (ClinicalTrials.gov identifiers: NCT03811002, NCT03703297), although a recently reported randomized phase II trial showed no improvement in PFS with nivolumab and ipilimumab following chemoradiation in this setting (25).

\section{BIOMARKERS OF RESPONSE AND RESISTANCE TO IMMUNOTHERAPY IN LUNG CANCER}

Despite the increasing role of immunotherapy and specifically PD-1/PD-L1 checkpoint inhibition in lung cancer, a substantial number of patients do not benefit from these therapies. In addition, immune-related toxicities occur in a subset of patients diminishing quality of life, adding to healthcare costs, and resulting in severe impairment or death $(26,27)$. Considering this, it is imperative that clinically useful predictive biomarkers be developed to appropriately choose those patients most likely to benefit and to avoid those with a small chance of efficacy and/or increased risk of toxicity.

\section{PD-L1 Expression}

With the exception of genomic driver mutations, PD-L1 is the only biomarker recommended by the National Comprehensive Cancer Network (NCCN) guidelines to aid in making treatment decisions in metastatic NSCLC (2). Multiple studies have demonstrated the predictive capability of this biomarker in stage IV NSCLC $(8,10,28)$. Nearly all these trials have suggested not only that PD-L1 expression levels can help with patient selection, but also, that the degree of immunotherapy benefit can be predicted by the magnitude of PD-L1 expression $(9,14,29,30)$. In contrast, there are several trials which dispute the benefit of PD-L1 as a viable biomarker for predicting response to $\mathrm{PD}-1 / \mathrm{PD}-\mathrm{L} 1$ checkpoint inhibitors $(6,7,31)$.

The predictive role of PD-L1 expression in the non-metastatic setting is gradually transpiring. In PACIFIC trial, PD-L1 negative patients exhibited less robust PFS and OS compared to PD-L1 positive patients following treatment with durvalumab (32). In contrast to this, correlative analysis of a smaller phase II trial of consolidation pembrolizumab after chemoradiation showed no difference in outcomes for PD-L1 positive versus negative patients (33). In the adjuvant setting, DFS was improved with atezolizumab following surgery and adjuvant chemotherapy only in the PDL1 $\geq 1 \%$ group, with the PD-L1 $\geq 50 \%$ group exhibiting the largest benefit (22).

\section{Tumor Mutational Burden (TMB)}

TMB is defined as the total number of mutations per megabase $\mathrm{Mb})$ of exonic regions of evaluated genes in a tumor specimen. As the number of mutations increases, the potential number of new transcribed proteins and neoantigens also goes up. This increase in neoantigen presence is hypothesized to enhance tumor immunogenicity and improve the likelihood that patients respond to checkpoint inhibition. Tissue and blood based TMB have been studied in several lung cancer and tumor agnostic studies and have been shown to predict benefit from various ICI $(9,13,30,31)$. More recently, the FDA has approved pembrolizumab for patients with any tumor type that demonstrates a high TMB ( $\geq 10$ mut/ $\mathrm{Mb}$ ) following results of the KEYNOTE-158 trial (34). Studies evaluating the combination of PD-L1 and TMB as a composite biomarker have suggested improved predictive capability for the combination $(31,35)$.

There are no clinically useful biomarkers to help guide the use of ICIs in extensive stage SCLC. Despite presenting with immune-mediated paraneoplastic syndromes and often exhibiting high TMB, SCLC does not typically demonstrate the same clinical benefit to checkpoint inhibition that is seen in NSCLC. The landmark clinical trials establishing the role of ICI in combination with chemotherapy in first-line treatment of extensive-stage SCLC did not demonstrate any discernible difference in response rates or clinical utility of ICI for any PD-L1 subgroup $(36,37)$.

\section{Specific Genomic Alterations}

There is some data to suggest that specific genomic alterations may predict better or worse responses to ICI. Much of this research has focused on determining genomic markers for immunotherapy resistance. STK11/LKB1 is a distinct subgroup of Kirsten Rat Sarcoma Virus (KRAS)- mutant lung adenocarcinoma. Some studies have suggested that the presence of KRAS mutation is a predictive of superior response rates from ICIs (38). However, specific co-mutations such as STK11/LKB1 have demonstrated poor immunogenic responses. In two separate lung adenocarcinoma cohorts, patients with KRAS and STK11/LKB1 co-mutations showed lower ORR compared with KRAS mutation alone and one of the cohorts noted a significantly lower PFS and OS during immunotherapy treatment (39). A second retrospective trial of patients with STK11 alone and STK11/KRAS co-mutations treated with immunotherapy showed poorer OS and PFS for those with STK11 mutations versus their STK11-wildtype counterparts (40). However, this study also notes poorer outcomes for STK11mutant patients when treated with chemotherapy, and an additional analysis suggests that poor outcomes in this population are prognostic rather than predictive of poor immune response (41)

Data has also been presented for ICI response in patients with common 'targetable' genomic alterations such as EGFR mutations and ALK fusions. Retrospective studies have demonstrated very low response rates with ICI in EGFR mutant NSCLC compared to EGFR wildtype tumors $(42,43)$. Prospective trials of ICI monotherapy in patients with EGFR mutant NSCLC have yielded similarly disappointing results (36, 44). Though the data is more scarce, patients with ALK gene rearrangements also appear to demonstrate poor responses to ICI monotherapy $(36,45)$.

\section{Circulating Tumor DNA (ctDNA)}

Analysis of any tumor-derived material circulating in the peripheral blood, also called 'Liquid Biopsy', is gaining increasing popularity in oncology because of its feasibility and 
relatively rapid turnaround time. Of the multitude of bloodbased biomarker analyses, circulating tumor DNA (ctDNA) is the most commonly used modality (46). The role of ctDNA analysis in the context of ICI therapy in lung cancer is currently limited to detection of specific genomic alterations noted above. Several commercial platforms are offering blood-based TMB assays, however, their clinical utility is yet to be validated in large prospective trials. Early data from studies looking at serial monitoring of ctDNA as a biomarker of response and survival with ICI show promising correlation between molecular and radiographic response (47). With well-designed future studies on a larger scale, it is conceivable that the depth of molecular response will guide the optimum duration of ICI therapy in future, a question that remains largely unanswered at this time.

\section{CHALLENGES FACING ICI THERAPY IN LUNG CANCER}

The unprecedented success of ICIs in the treatment of lung cancer is not without several major challenges. Firstly, nearly $70 \%$ of patients with advanced NSCLC and $80 \%$ of patients with SCLC do not derive durable benefit from ICI based therapies. Putative mechanisms of inherent or acquired resistance to ICI include T-cell exhaustion, coexpression of inhibitory receptors, altered metabolism through Indoleamine 2, 3-dioxygenase 1 (IDO-1) and increased adenosine production, high copy number loss of tumor suppressor genes, and decreased antigen presentation (48). Second, as noted above, the quest for a perfect and reliable biomarker of response to ICI is still ongoing. While PD-L1 expression is the most widely used biomarker in clinical practice, its predictive value is not absolute. Inter-tumor and intra-tumor heterogeneity of PD-L1 expression, a wide variety of PD-L1 assays and cutoff values utilized to define PDL1 positivity, and the effect of handling and storage of tumor tissue on PD-L1 analysis render it an imperfect biomarker (11, 49-52). Studies have shown significant discordance in PD-L1 expression between lung biopsies and corresponding resected tumors, between primary and metastatic sites, and among different metastatic sites (53-55). Finally, SCLC remains an invincible enemy with only a limited success achieved with incorporation of currently available ICIs in the treatment paradigm, largely driven by an immunosuppressive tumor microenvironment (TME) (56). These challenges have warranted development of novel approaches to harness the power of the immune system in combating this historically relentless disease.

\section{IMMUNOTHERAPY APPROACHES BEYOND PD-1/PD-L1 AND CTLA-4 INHIBITION IN LUNG CANCER}

\section{Novel Immune Checkpoint Targets}

As noted above, PD-1/PD-L1 and CTLA-4 inhibitors are the most commonly used ICIs in lung cancer, yet development of resistance to these agents remains an insurmountable challenge. In recent years, inhibitors of novel immune checkpoint targets have shown encouraging results in pre-clinical and early clinical studies, potentiating the pursuit of new therapeutic strategies to overcome the resistance to conventional ICIs.

\section{T-Cell Immunoreceptor With Ig and ITIM Domains (TIGIT)}

TIGIT is a promising new immune checkpoint. It is expressed on activated T cells, natural killer (NK) cells, and regulatory $\mathrm{T}$ cells (Tregs). TIGIT binds to two ligands, CD155 (PVR) and CD112 (PVRL2, nectin-2), that are expressed by tumor cells and antigenpresenting cells in the tumor microenvironment (57). Dual PD-1/ TIGIT blockade potently increases tumor antigen-specific CD8+ T cell expansion and function in vitro and promotes tumor rejection in mouse tumor models $(58,59)$. In a recently reported randomized phase II trial, combination of anti-TIGIT antibody tiragolumab with atezolizumab led to clinically meaningful improvement in ORR and PFS compared to placebo plus atezolizumab as first-line treatment of patients with advanced, PD-L1 positive NSCLC (60). Based on these results FDA has granted breakthrough therapy designation to tiragolumab in NSCLC. A confirmatory phase III trial is ongoing in this patient population (ClinicalTrials.gov identifier: NCT04294810). Early results from a phase I trial of another anti-TIGIT antibody vibostolimab has shown clinical activity in combination with pembrolizumab in $\mathrm{PD}-1 / \mathrm{PD}-\mathrm{L} 1$ naïve and refractory patients with advanced NSCLC (61). An ongoing phase III trial is comparing combination of vibostolimab plus pembrolizumab with pembrolizumab alone in patients with $\mathrm{PD}$-L1 positive advanced NSCLC (ClinicalTrials.gov identifier: NCT04738487).

\section{Lymphocyte Activation Gene-3 (LAG-3)}

LAG-3 is expressed on activated CD4+ and CD8+ T cells, Tregs, a subpopulation of NK cells, B cells, and plasmacytoid dendritic cells (pDCs). LAG-3 signaling plays a negative regulatory role in $\mathrm{T}$ helper 1 (Th1) cell activation, proliferation and cytokine secretion, a function that is exploited by tumor cells to evade the host immune system (62). Among several different LAG-3 inhibitors under development, monoclonal antibody relatlimab, is farthest along in clinical trials. The combination of relatlimab with nivolumab has shown significant improvement in PFS compared to nivolumab alone in patients with melanoma (63). A phase II trial evaluating the efficacy of relatlimab in combination with nivolumab and chemotherapy as first-line treatment of advanced NSCLC is currently ongoing (ClinicalTrials.gov identifier: NCT04623775).

\section{T-Cell Immunoglobulin and Mucin-Domain Containing-3 (TIM-3)}

TIM-3, a negative regulator of $\mathrm{T}$ cell response and also called hepatitis A virus cellular receptor 2 (HAVCR2), expressed on CD4+ and CD8+ T cells, NK cells, DCs, Tregs, monocytes, and macrophages, is another emerging immune checkpoint (64). Higher expression of TIM-3 has been associated with poor prognosis in solid malignancies and inhibition of TIM-3 in combination with PD-1 inhibition has been shown to have anti-tumor activity $(65,66)$. At least eight different TIM-3 
inhibitors are in development and have shown superior efficacy of simultaneous inhibition of TIM-3 pathway and PD-1 pathway over single-agent treatment (67).

\section{NK Group 2 Member A (NKG2A)}

NKG2A is a cell surface molecule, which is typically expressed by NK cells, but expression can be induced on T cells as well, especially on CD8+ T cells (68). HLA-E, a ligand of NKG2A, expression has been demonstrated to have immunosuppressive function through binding to NKG2A (69). Overexpression of HLA-E on cancer cells has been correlated with poor outcomes (70). Monalizumab, a monoclonal antibody targeting NKG2A, has shown promising antitumor activity in early clinical trials in lung cancer, including recently reported interim analysis of a phase II trial showing improved ORR and PFS with monalizumab in combination with durvalumab compared to durvalumab alone in patients with unresectable, Stage III NSCLC who did not progress after concurrent chemoradiation therapy (71).

\section{CD73}

CD73, an ecto-5'-nucleotidase (NT5E), serves as an immune checkpoint by generating adenosine which suppresses immune activation through the A2A receptor (72). CD73 is upregulated in a variety of tumors including lung cancer, and higher expression of CD73 in the tumor tissue is associated with poor outcomes (72-75). Preclinical studies have established a strong foundation for evaluating CD73 inhibition in combination with PD-1/PD-L1 inhibition by demonstrating synergistic anti-tumor activity through augmentation of intra-tumoral infiltration of CD8+ tumor-specific $\mathrm{T}$ cells $(76,77)$. Recently reported early results of a phase II clinical trial evaluating oleclumab, a monoclonal antibody against CD73, in combination with durvalumab following chemoradiation in locally advanced unresectable stage III NSCLC showed improved PFS with the combination compared to durvalumab alone, with a manageable safety profile (78). A number of trials are underway to evaluate oleclumab containing regimens in lung cancer.

Apart from these, several other immune checkpoint targets are under investigation, including $\mathrm{V}$-domain immunoglobulin suppressor of T cell activation (VISTA), B7-H3 (CD276), IDO-1, glucocorticoid-induced TNFR-related receptor (GITR), and CD47. A multitude of ongoing clinical trials are evaluating inhibitors of these targets by themselves and in combination with PD-1/PD-L1 inhibition (Table 1).

\section{Combination with Conventional Therapeutic Strategies \\ Chemotherapy}

As noted above, chemotherapy in combination with ICI has shown superiority over chemotherapy alone in several randomized controlled trials in NSCLC and SCLC. In these trials, patients typically received 4 cycles of platinum-based chemotherapy in combination with ICI followed by maintenance ICI alone or pemetrexed plus ICI in case of nonsquamous NSCLC. Subsequently, CheckMate-9LA trial demonstrated feasibility of using shorter duration, i.e. 2 cycles, of chemotherapy in combination with PD-1 and CTLA-4 inhibitors without comprising the efficacy of the regimen (17). While the synergistic activity of ICIs in combination with chemotherapy is well established and that the addition of ICI may allow for shorter duration of chemotherapy, several questions remain unanswered, including the optimum number of chemotherapy cycles in the initial induction phase, whether pemetrexed continuation is critical in the maintenance phase for non-squamous NSCLC, predictive biomarkers to inform decision making with regards to the duration of chemoimmunotherapy, and value of adding ICI to second-line chemotherapy following progression on first-line chemoimmunotherapy.

\section{Radiation}

The immunomodulatory effects of radiation are well established and include a shift in tumor associated macrophage polarization, activation of tumor-associated dendritic cells, improved T-cell homing to tumors, destruction of immunosuppressive stromal cells within the TME, and induction of immunogenic cell death (79). Consequently, combining ICI with radiation, either concurrently or sequentially, has been an area of great interest. A number of clinical trials have been initiated to build on the success of PACIFIC trial with consolidation durvalumab following chemoradiation in patients with locally advanced unresectable NSCLC. A notable concern with combining ICI with radiation is the development of toxicity, specifically pneumonitis. In a phase II trial of pembrolizumab with concurrent chemoradiation, the rate of grade $\geq 3$ pneumonitis was $8 \%$ compared to $3.4 \%$ reported in PACIFIC trial (80). Future approaches directed towards modifying the dosing and schedule of radiation when used in close proximity with ICI may enhance the feasibility and minimize toxicity of this approach.

\section{Targeted Therapy}

The list of actionable genomic alterations in NSCLC and corresponding targeted therapeutic approaches have expanded considerably in the recent years. Retrospective studies and subset analyses of prospective trials have shown limited efficacy of ICIs in patients with NSCLC harboring targetable driver alterations $(43,81)$. Combination of ICIs with EGFR and ALK tyrosine kinase inhibitors has shown increase in severe treatment related toxicity, including pneumonitis and liver dysfunction, with no added clinical activity (82). KRAS mutation is perhaps an exception to this limitation. KRAS G12C inhibitors have shown development of pro-inflammatory TME and durable responses alone as well as in combination with ICIs in mice models (83). Clinical trials combining ICIs with currently available KRAS G12C inhibitors, sotorasib and adagrasib, are ongoing (ClinicalTrials.gov identifiers: NCT04185883, NCT04613596).

\section{Combination With DNA Repair Targeting Agents}

DNA damage is a hallmark of lung cancer and is most apparent in smoking induced NSCLC and SCLC (84). Smoking induced DNA damage triggers several DNA response pathways (85). Accurate and faithful DNA replication is critical for maintenance of genomic stability in all cellular divisions including that of 
TABLE 1 | Novel immune checkpoint inhibitors and ongoing clinical trials.

\begin{tabular}{|c|c|c|c|c|}
\hline Target & Proposed function & Drug & $\begin{array}{l}\text { ClinicalTrials.gov } \\
\text { Identifier }\end{array}$ & Phase \\
\hline \multirow[t]{11}{*}{ TIGIT } & \multirow{11}{*}{$\begin{array}{l}\text { Inhibitory receptor on activated T-cells that binds to CD155 and CD112 on } \\
\text { tumor cells }\end{array}$} & \multirow[t]{6}{*}{ Tiragolumab (anti TIGIT mAb) } & NCT04256421 & III \\
\hline & & & NCT04294810 & III \\
\hline & & & NCT04513925 & III \\
\hline & & & NCT04619797 & $\|$ \\
\hline & & & NCT04832854 & $\|$ \\
\hline & & & NCT04308785 & $\|$ \\
\hline & & \multirow{5}{*}{$\begin{array}{l}\text { Vibostolimab } \\
\text { (anti TIGIT mAb) } \\
\text { Domvanalimab (anti TIGIT mAb) }\end{array}$} & NCT04738487 & III \\
\hline & & & NCT02964013 & I \\
\hline & & & NCT04736173 & III \\
\hline & & & NCT04262856 & $\|$ \\
\hline & & & NCT04791839 & $\|$ \\
\hline \multirow[t]{3}{*}{ LAG 3} & \multirow[t]{3}{*}{ Inhibitory co-receptor in T-cell stimulation } & $\begin{array}{l}\text { Eftilagimod alpha (soluble LAG-3 fusion } \\
\text { protein) }\end{array}$ & NCT03625323 & $\|$ \\
\hline & & Relatlimab (anti LAG3 mAb) & NCT04623775 & $\|$ \\
\hline & & BI 754111 (anti LAG3 mAb) & NCT03156114 & । \\
\hline \multirow[t]{3}{*}{ TIM-3 } & \multirow[t]{3}{*}{ Inhibitory receptor on CD4+ and CD8+ cells that causes Th1 suppression } & $\begin{array}{l}\text { RO7121661 (bispecific anti TIM-3/anti- } \\
\text { PD1 mAb) }\end{array}$ & NCT03708328 & 1 \\
\hline & & MGB453 (anti-TIM3-mAb) & NCT02608268 & 1 \\
\hline & & TSR-022 (anti-TIM-3 mAb) & NCT03307785 & 1 \\
\hline \multirow[t]{3}{*}{ NKG2A } & \multirow[t]{3}{*}{ Inhibitory receptor on NK and CD8+ T cells } & Monalizumab & NCT03833440 & $\|$ \\
\hline & & (anti NKG2A mAb) & NCT03822351 & $\|$ \\
\hline & & & NCT05061550 & $\|$ \\
\hline \multirow[t]{3}{*}{ CD73 } & \multirow{3}{*}{$\begin{array}{l}\text { Generates adenosine which suppresses immune activation through A2A } \\
\text { receptor }\end{array}$} & Oleclumab & NCT05061550 & $\|$ \\
\hline & & (anti CD73 mAb) & NCT03822351 & $\|$ \\
\hline & & & NCT03334617 & $\|$ \\
\hline \multirow[t]{4}{*}{ IDO-1 } & \multirow{4}{*}{$\begin{array}{l}\text { Enzyme on tumor cells that metabolizes tryptophan to kynurenine and } \\
\text { subsequently inhibits T-cell differentiation }\end{array}$} & LY3381916 (IDO-1 inhibitor) & NCT03343613 & 1 \\
\hline & & Epacadostat (IDO-1 inhibitor) & NCT03322540 & $\|$ \\
\hline & & & NCT03322566 & $\|$ \\
\hline & & Indoximod (IDO-1 inhibitor) & NCT02460367 & 1 \\
\hline \multirow[t]{2}{*}{ B7-H3 } & \multirow[t]{2}{*}{ Inhibitor of CD4+ and CD8+ cells, decreases IL2 and IFN- $\gamma$ production } & \multirow[t]{2}{*}{ Enoblituzumab (anti B7-H3 mAb) } & NCT02381314 & । \\
\hline & & & NCT02475213 & 1 \\
\hline \multirow[t]{2}{*}{ CD27 } & \multirow{2}{*}{$\begin{array}{l}\text { Expressed on T-cells; agonism thought to stimulate effector T-cells and } \\
\text { repress T-regs }\end{array}$} & \multirow[t]{2}{*}{ Varlilumab (anti-CD27 mAb) } & NCT01460134 & 1 \\
\hline & & & NCT04081688 & 1 \\
\hline \multirow[t]{2}{*}{ GITR } & \multirow[t]{2}{*}{$\begin{array}{l}\text { GITR receptor binding with GITR-ligand promotes tumor cell apoptosis and } \\
\text { increased activity of T-cells and NK cells }\end{array}$} & $\begin{array}{l}\text { MEDI1873 (GITRL/lgG1 agonist fusion } \\
\text { protein) }\end{array}$ & NCT02583165 & I \\
\hline & & BMS-986156 (lgG1 agonist mAb to GITR) & NCT04021043 & $|/| \mid$ \\
\hline \multirow[t]{2}{*}{$\begin{array}{l}\text { CD47 and } \\
\text { SIRP } \alpha\end{array}$} & \multirow[t]{2}{*}{$\begin{array}{l}\text { CD47 (overexpressed on tumor cells) binds to SIRP } \alpha \text { receptor on myeloid cells } \\
\text { and restricts phagocytosis }\end{array}$} & $\begin{array}{l}\text { TTI-621(soluble recombinant fusion } \\
\text { protein against CD47) }\end{array}$ & NCT02663518 & 1 \\
\hline & & Magrolimab (anti CD47 mAb) & NCT04827576 & $\|$ \\
\hline VISTA & Homologous to PD-L1; suppresses T-cell proliferation & $\begin{array}{l}\text { CA-170 (oral PD-L1, PD-L2 and VISTA } \\
\text { checkpoint antagonist) }\end{array}$ & NCT02812875 & I \\
\hline
\end{tabular}

TIGIT, T cell immunoreceptor with Ig and ITIM domains; mAb, monoclonal antibody; LAG-3, Lymphocyte activation gene 3; TIM-3, T-cell immunoglobulin and mucin-domain containing-3; NKG2A, NK group 2 member A; CD73, Cluster of differentiation 73; IDO1, Indoleamine 2, 3-dioxygenase 1; B7-H3, B7 homolog 3; IFN- $\gamma$, Interferon Gamma; CD27, Cluster of differentiation 27; GITR, glucocorticoid-induced TNFR-related receptor; CD47 and SIRP $\alpha$, Cluster of differentiation 47 and Signal Regulatory Protein Alpha; VISTA, V-domain immunoglobulin suppressor of T cell activation; IL-2, Interleukin 2; T-regs, Regulatory T-cells; NK cells, Natural Killer Cells; PD-L1, Programmed Death-Ligand 1.

immune cells $(86,87)$. While traditionally DNA repair has been studied in the context of sensitivity to platinum-based chemotherapy and PARP inhibition, mounting evidence suggests the role of DNA repair defects in predicting response to ICIs in a variety of tumors, including NSCLC (88-91). A wellknown example is the efficacy of pembrolizumab in mismatch repair deficient tumors irrespective of PD-L1 expression (92). Germline mutations in BRCA2 or POLE have also been connected to increased ICI sensitivity $(93,94)$. A retrospective study has shown strong association of somatic BRCA1, PALB2, and POLE mutations with high TMB in NSCLC (95). The precise mechanisms behind the association of DNA repair defects and response to ICI, however, remain poorly understood. Genomic instability resulting from these defects, higher neoantigen load and TMB, and association with activation of cGAS-STING pathway are among the postulated key players $(90,96)$.

In addition to utilizing DNA repair defects in predicting response to ICI in lung cancer, an increasing amount of research is focusing on the prospect of combining ICIs with DNA repair targeting agents in NSCLC. Perhaps the farthest along in this race are PARP inhibitors and ATR inhibitors. Preclinical studies have shown upregulation of PD-L1 expression with PARP inhibition, re-sensitization of PARP inhibitor treated cancer cells to T-cell mediated killing through PD-L1 blockade, and enhanced in vivo therapeutic efficacy of PARP inhibition in combination with anti-PD-L1 therapy (97). Three large ongoing clinical trials are evaluating the efficacy and safety of combination of ICI with PARP inhibitor in NSCLC, including 
KEYLINK-006 (ClinicalTrials.gov identifier: NCT03976323), KEYLINK-008 (ClinicalTrials.gov identifier: NCT03976362), and ORION (ClinicalTrials.gov identifier: NCT03775486). Similarly, a trial of ATR inhibitor ceralasertib evaluating its combination with paclitaxel in patients with a variety of solid organ malignancies showed upregulation of PD-L1 expression in paired tumor samples following treatment with ceralasertib (98). As a result of this initial finding, an ongoing study is evaluating combination of ceralasertib with durvalumab in patients with advanced NSCLC following progression on ICI therapy (ClinicalTrials.gov Identifier: NCT03334617). While these studies are being conducted in all NSCLC patients, it remains unclear whether the benefit of such combinations will be restricted to those with DNA repair defective tumors. Additionally, clinically feasible and reproducible biomarkers of DNA repair defects in lung cancer will need to be evaluated and validated in prospective studies.

Figure 1 illustrates novel immunotherapy targets and intersection with DNA repair in lung cancer.

\section{Cellular Therapy in Lung Cancer}

Immune cell-based therapy has recently emerged as a promising immunotherapeutic approach to target lung cancer (99). Building on successes in other tumors, immune cells have been exploited for their innate ability to eliminate cancer cells and mount powerful immune responses by recruiting other cells in the TME. To enhance specificity of immune recognition of cancer cells, genetic engineering of $\mathrm{T}$ - or NK cells has enabled these cells to target specific antigens expressed on lung cancer cells and reprogram the immune cells' behavior toward enhanced function. Most of the studies on immune cell-based targeting of lung cancer have been reported for CAR-T cells, though a growing body of work is exploiting the allogeneic nature of NK cells as potentially safer alternatives to infused CAR-T cells (100).

Engineered cell-based therapies for lung cancer have so far been designed to target epidermal growth factor receptor (EGFR) and variant III (EGFRviii), glypican 3 (GPC3), human epidermal growth factor receptor 2 (HER2), Protein tyrosine kinase 7 (PTK7), erythropoietin-producing hepatocellular carcinoma A2 (EphA2), mesothelin (MSLN), prostate stem cell antigen (PSCA), mucin 1 (MUC1), carcinoembryonic antigen (CEA), natural killer group 2D (NKG2D), tyrosine kinase-like orphan receptor 1 (ROR1), and programmed cell death ligand 1 (PDL1),lung-specific X (LunX), and delta-like 3 (DLL3) (101-104).

Future clinical development of cellular therapies targeting many of these antigens has been challenged by toxicities observed upon infusion of CAR-T products. For instance, infusion of ERBB2-specific CAR-T cells to treat a patient with colon cancer with metastasis to lungs and liver caused respiratory distress within 15 minutes of cell infusion (105). The authors of the study speculated that this was due to the high activity of CAR$\mathrm{T}$ cells in lungs following recognition of low levels of ERBB2 expression on lung epithelial cells, thus triggering intense, and toxic, cytokine production. Acute respiratory toxicities were also observed in a cohort of patients treated with CEACAM-5-directed CAR-T cells, again due to expression of CEACAM-5 on the lung epithelium (106). This was accompanied by high levels of IFN- $\gamma$ and IL-6. This lack of specificity for tumor expressed antigens is one of the major challenges to the clinical development of CAR-T cell therapies in solid tumors, specifically lung cancer.

Though the ideal antigen is one that is exclusively present on tumor cells and absent in healthy tissue, targeting approaches often must grapple with sub-optimal expression of targetable antigens due to their presence in surrounding healthy tissues. In addition to the non-specific nature of expression of many of the targetable antigens in lung cancer, antigen density is highly heterogeneous in the tumors, and their high genomic instability leads to antigen loss or outgrowth variants that can occur in response to persistence targeting by antigen-specific CAR-T cells (107). Antigen loss has spurred the development of engineering strategies that can induce genetic circuitry to immune cells and avoid antigen escape. These include dual or

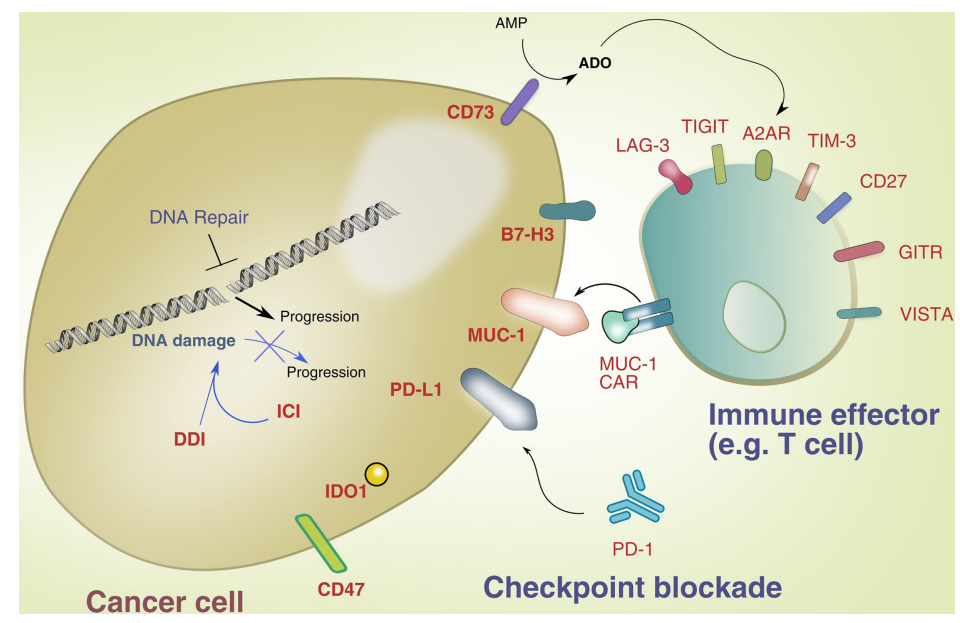

FIGURE 1 | Novel immunotherapy targets and intersection with DNA repair. 
multispecific CAR-T cells, CAR-T cell secreting antibodies such as $\mathrm{PD}-\mathrm{L} 1$, as well as trigger-responsive CAR-T cells (e.g. synNotch CAR-T cells, which are designed to target multiple antigens and enhance their specificity against the tumor $(108,109)$.

Despite the demonstrated successes with cell-based therapies with hematological malignancies, the response rates in solid tumors, including lung cancer, have been underwhelming. In lung cancer, the TME presents a complex barrier to the activity of immune cells which often results in resistance to treatment. The homing of CAR-T cells is poor due to several factors acting against them in the lung cancer TME. These include inadequate or mismatched chemokinechemokine receptor pairs, downregulation of adhesion molecules, aberrant vasculature, unfavorable extracellular matrix (ECM) composition, and immunometabolically adverse conditions such as hypoxia and the presence of immunosuppressive soluble metabolites and factors such as TGF- $\beta$, lactate and adenosine. In particular, in lung cancer, the structure of the ECM, composed of collagens, proteoglycans and glycosaminoglycans, has been reported as playing a significant role in the ability of immune cells to successfully home to lung tumors (110). In addition, dysfunction of infiltrating immune cells occurs due to unfavorable immunometabolic conditions in the tumor. Dysfunction, in the case of CAR-T cells, can manifest as exhaustion, senescence, or anergy (111). This results in inadequate immune responses and has triggered the development of "exhaustion-resistant" CAR-T cells, which are engineered by knocking out genes that contribute to T cell dysfunction, such as, in one case, TCR, HLA class I, PD-1, and CTLA4 using one-shot CRISPR (112). Recent studies have also shown that blocking the adenosine pathway by inhibiting activity of CD73 can enhance immune cell activity and infiltration into lung cancer in preclinical mouse models (113). In these studies, NK cells engineered to target NKG2D on lung cancer were combined with antibodymediated blockade of CD73 and resulted in deeper intratumoral infiltration and killing ability of these cells.

\section{REFERENCES}

1. Howlader N, Forjaz G, Mooradian MJ, Meza R, Kong CY, Cronin KA, et al. The Effect of Advances in Lung-Cancer Treatment on Population Mortality. N Engl J Med (2020) 383(7):640-9. doi: 10.1056/NEJMoa1916623

2. Network NCC. Non-Small Cell Lung Cancer (Version 7.2021). Available at: https://www.nccn.org/professionals/physician_gls/pdf/nscl.pdf.

3. Alexandrov LB, Nik-Zainal S, Wedge DC, Aparicio SA, Behjati S, Biankin $\mathrm{AV}$, et al. Signatures of Mutational Processes in Human Cancer. Nature (2013) 500(7463):415-21. doi: 10.1038/nature12477

4. Pardoll DM. The Blockade of Immune Checkpoints in Cancer Immunotherapy. Nat Rev Cancer (2012) 12(4):252-64. doi: 10.1038/nrc3239

5. The Nobel Prize in Physiology or Medicine 2018 [Press Release] Stockholm: The Nobel Assembly at Karolinska Institutet 2018 (2018). Available at: https://www.nobelprize.org/prizes/medicine/2018/press-release/.

6. Borghaei H, Paz-Ares L, Horn L, Spigel DR, Steins M, Ready NE, et al. Nivolumab Versus Docetaxel in Advanced Nonsquamous Non-Small-Cell Lung Cancer. N Engl J Med (2015) 373(17):1627-39. doi: 10.1056/ NEJMoa 1507643

7. Brahmer J, Reckamp KL, Baas P, Crino L, Eberhardt WE, Poddubskaya E, et al. Nivolumab Versus Docetaxel in Advanced Squamous-Cell Non-SmallCell Lung Cancer. N Engl J Med (2015) 373(2):123-35. doi: 10.1056/ NEJMoa1504627
Finally, CAR-T cells themselves can cause toxicities upon systemic administration. Severe and sometimes lethal cytokine levels have been measured in patients treated with CAR T cells in many clinical trials, not exclusive to lung cancer (114). Mitigation measures include antibody therapy to reduce the burden of cytokine release syndrome, engineering safety switch-based CAR-T cells, or using NK cells. Local administration of immune cell therapies is currently under preclinical and clinical investigation as an approach to directly drive cells to the tumor.

\section{CONCLUSION}

The landscape of immunotherapy in lung cancer is rapidly expanding and ICIs have become the standard of care treatment for patients with metastatic, locally advanced, and resectable NSCLC with remarkable improvement in OS. The clinical utility of ICI in SCLC is limited to first-line therapy of extensive-stage disease with small improvement in OS. Resistance to immunotherapy, either inherent or acquired, is a major challenge facing the Oncology community. Cellular therapy is a promising and potent addition to the arsenal of immunotherapies for lung cancer. Lack of tumor-specific antigens, hostile TME, and toxicity make cellular therapy an exciting, but undeniably challenging, proposition. Development of novel treatment strategies, including combination and sequencing of PD-1/PD-L1 inhibitors with other ICIs and DNA repair targeting agents, are being evaluated in clinical trials.

\section{AUTHOR CONTRIBUTIONS}

All authors listed have made a substantial, direct, and intellectual contribution to the work, and approved it for publication.

8. Herbst RS, Baas P, Kim DW, Felip E, Perez-Gracia JL, Han JY, et al. Pembrolizumab Versus Docetaxel for Previously Treated, PD-L1-Positive, Advanced Non-Small-Cell Lung Cancer (KEYNOTE-010): A Randomised Controlled Trial. Lancet (2016) 387(10027):1540-50. doi: 10.1016/S01406736(15)01281-7

9. Rittmeyer A, Barlesi F, Waterkamp D, Park K, Ciardiello F, von Pawel J, et al. Atezolizumab Versus Docetaxel in Patients With Previously Treated Non-Small-Cell Lung Cancer (OAK): A Phase 3, Open-Label, Multicentre Randomised Controlled Trial. Lancet (2017) 389(10066):255-65. doi: 10.1016/S0140-6736(16)32517-X

10. Reck M, Rodriguez-Abreu D, Robinson AG, Hui R, Csoszi T, Fulop A, et al. Pembrolizumab Versus Chemotherapy for PD-L1-Positive Non-Small-Cell Lung Cancer. N Engl J Med (2016) 375(19):1823-33. doi: 10.1056/NEJMoa1606774

11. Herbst RS, Giaccone G, de Marinis F, Reinmuth N, Vergnenegre A, Barrios CH, et al. Atezolizumab for First-Line Treatment of PD-L1-Selected Patients With NSCLC. N Engl J Med (2020) 383(14):1328-39. doi: 10.1056/NEJMoa1917346

12. Sezer A, Kilickap S, Gumus M, Bondarenko I, Ozguroglu M, Gogishvili M, et al. Cemiplimab Monotherapy for First-Line Treatment of Advanced NonSmall-Cell Lung Cancer With PD-L1 of at Least 50\%: A Multicentre, OpenLabel, Global, Phase 3, Randomised, Controlled Trial. Lancet (2021) 397 (10274):592-604. doi: 10.1016/S0140-6736(21)00228-2

13. Hellmann MD, Paz-Ares L, Bernabe Caro R, Zurawski B, Kim SW, Carcereny Costa E, et al. Nivolumab Plus Ipilimumab in Advanced Non- 
Small-Cell Lung Cancer. N Engl J Med (2019) 381(21):2020-31. doi: 10.1056/NEJMoa1910231

14. Gandhi L, Rodriguez-Abreu D, Gadgeel S, Esteban E, Felip E, De Angelis F, et al. Pembrolizumab Plus Chemotherapy in Metastatic Non-Small-Cell Lung Cancer. N Engl J Med (2018) 378(22):2078-92. doi: 10.1056/ NEJMoa1801005

15. Paz-Ares L, Luft A, Vicente D, Tafreshi A, Gumus M, Mazieres J, et al. Pembrolizumab Plus Chemotherapy for Squamous Non-Small-Cell Lung Cancer. N Engl J Med (2018) 379(21):2040-51. doi: 10.1056/ NEJMoa1810865

16. Socinski MA, Jotte RM, Cappuzzo F, Orlandi F, Stroyakovskiy D, Nogami N, et al. Atezolizumab for First-Line Treatment of Metastatic Nonsquamous NSCLC. N Engl J Med (2018) 378(24):2288-301. doi: 10.1056/ NEJMoa1716948

17. Paz-Ares L, Ciuleanu TE, Cobo M, Schenker M, Zurawski B, Menezes J, et al. First-Line Nivolumab Plus Ipilimumab Combined With Two Cycles of Chemotherapy in Patients With Non-Small-Cell Lung Cancer (Checkmate 9LA): An International, Randomised, Open-Label, Phase 3 Trial. Lancet Oncol (2021) 22(2):198-211. doi: 10.1016/S1470-2045(20)30641-0

18. Reck M, Rodriguez-Abreu D, Robinson AG, Hui R, Csoszi T, Fulop A, et al. Five-Year Outcomes With Pembrolizumab Versus Chemotherapy for Metastatic Non-Small-Cell Lung Cancer With PD-L1 Tumor Proportion Score $>/=50$. J Clin Oncol (2021) 39(21):2339-49. doi: 10.1200/ JCO.21.00174

19. Borghaei H, Gettinger S, Vokes EE, Chow LQM, Burgio MA, de Castro Carpeno J, et al. Five-Year Outcomes From the Randomized, Phase III Trials Checkmate 017 and 057: Nivolumab Versus Docetaxel in Previously Treated Non-Small-Cell Lung Cancer. J Clin Oncol (2021) 39(7):723-33. doi: 10.1200/JCO.20.01605

20. Antonia SJ, Villegas A, Daniel D, Vicente D, Murakami S, Hui R, et al. Durvalumab After Chemoradiotherapy in Stage III Non-Small-Cell Lung Cancer. N Engl J Med (2017) 377(20):1919-29. doi: 10.1056/ NEJMoa1709937

21. Spigel DR, Faivre-Finn C, Gray JE, Vicente D, Planchard D, Paz-Ares LG, et al. Five-Year Survival Outcomes With Durvalumab After Chemoradiotherapy in Unresectable Stage III NSCLC: An Update From the PACIFIC Trial. J Clin Oncol (2021) 39:(15_suppl):8511-. doi: 10.1200/ JCO.2021.39.15_suppl.8511

22. Felip E, Altorki N, Zhou C, Csoszi T, Vynnychenko I, Goloborodko O, et al. Adjuvant Atezolizumab After Adjuvant Chemotherapy in Resected Stage IBIIIA Non-Small-Cell Lung Cancer (Impower010): A Randomised, Multicentre, Open-Label, Phase 3 Trial. Lancet (2021) 398(10308):134457. doi: 10.1016/S0140-6736(21)02098-5

23. Horn L, Mansfield AS, Szczesna A, Havel L, Krzakowski M, Hochmair MJ, et al. First-Line Atezolizumab Plus Chemotherapy in Extensive-Stage SmallCell Lung Cancer. N Engl J Med (2018) 379(23):2220-9. doi: 10.1056/ NEJMoa1809064

24. Paz-Ares L, Dvorkin M, Chen Y, Reinmuth N, Hotta K, Trukhin D, et al. Durvalumab Plus Platinum-Etoposide Versus Platinum-Etoposide in FirstLine Treatment of Extensive-Stage Small-Cell Lung Cancer (CASPIAN): A Randomised, Controlled, Open-Label, Phase 3 Trial. Lancet (2019) 394 (10212):1929-39. doi: 10.1016/S0140-6736(19)32222-6

25. Peters S, Pujol JL, Dafni U, Domine M, Popat S, Reck M, et al. Consolidation Nivolumab and Ipilimumab Versus Observation in Limited-Disease SmallCell Lung Cancer After Chemo-Radiotherapy - Results From the Randomised Phase II ETOP/IFCT 4-12 STIMULI Trial. Ann Oncol (2021) 33(1):67-79. doi: 10.1016/j.annonc.2020.08.2326

26. Camidge DR, Doebele RC, Kerr KM. Comparing and Contrasting Predictive Biomarkers for Immunotherapy and Targeted Therapy of NSCLC. Nat Rev Clin Oncol (2019) 16(6):341-55. doi: 10.1038/s41571-019-0173-9

27. Suresh K, Naidoo J, Lin CT, Danoff S. Immune Checkpoint Immunotherapy for Non-Small Cell Lung Cancer: Benefits and Pulmonary Toxicities. Chest (2018) 154(6):1416-23. doi: 10.1016/j.chest.2018.08.1048

28. Garon EB, Rizvi NA, Hui R, Leighl N, Balmanoukian AS, Eder JP, et al. Pembrolizumab for the Treatment of Non-Small-Cell Lung Cancer. N Engl J Med (2015) 372(21):2018-28. doi: 10.1056/NEJMoa1501824

29. Nosaki K, Saka H, Hosomi Y, Baas P, de Castro GJr., Reck M, et al. Safety and Efficacy of Pembrolizumab Monotherapy in Elderly Patients With PD-
L1-Positive Advanced Non-Small-Cell Lung Cancer: Pooled Analysis From the KEYNOTE-010, KEYNOTE-024, and KEYNOTE-042 Studies. Lung Cancer (2019) 135:188-95. doi: 10.1016/j.lungcan.2019.07.004

30. Fehrenbacher L, Spira A, Ballinger M, Kowanetz M, Vansteenkiste J, Mazieres J, et al. Atezolizumab Versus Docetaxel for Patients With Previously Treated Non-Small-Cell Lung Cancer (POPLAR): A Multicentre, Open-Label, Phase 2 Randomised Controlled Trial. Lancet (2016) 387(10030):1837-46. doi: 10.1016/S0140-6736(16)00587-0

31. Carbone DP, Reck M, Paz-Ares L, Creelan B, Horn L, Steins M, et al. FirstLine Nivolumab in Stage IV or Recurrent Non-Small-Cell Lung Cancer. N Engl J Med (2017) 376(25):2415-26. doi: 10.1056/NEJMoa1613493

32. Paz-Ares L, Spira A, Raben D, Planchard D, Cho BC, Ozguroglu M, et al. Outcomes With Durvalumab by Tumour PD-L1 Expression in Unresectable, Stage III Non-Small-Cell Lung Cancer in the PACIFIC Trial. Ann Oncol (2020) 31(6):798-806. doi: 10.1016/j.annonc.2020.03.287

33. Durm GA, Jabbour SK, Althouse SK, Liu Z, Sadiq AA, Zon RT, et al. A Phase 2 Trial of Consolidation Pembrolizumab Following Concurrent Chemoradiation for Patients With Unresectable Stage III Non-Small Cell Lung Cancer: Hoosier Cancer Research Network LUN 14-179. Cancer (2020) 126(19):4353-61. doi: 10.1002/cncr.33083

34. Marabelle A, Fakih M, Lopez J, Shah M, Shapira-Frommer R, Nakagawa K, et al. Association of Tumour Mutational Burden With Outcomes in Patients With Advanced Solid Tumours Treated With Pembrolizumab: Prospective Biomarker Analysis of the Multicohort, Open-Label, Phase 2 KEYNOTE158 Study. Lancet Oncol (2020) 21(10):1353-65. doi: 10.1016/S1470-2045 (20)30445-9

35. Rizvi H, Sanchez-Vega F, La K, Chatila W, Jonsson P, Halpenny D, et al. Molecular Determinants of Response to Anti-Programmed Cell Death (PD)-1 and Anti-Programmed Death-Ligand 1 (PD-L1) Blockade in Patients With Non-Small-Cell Lung Cancer Profiled With Targeted Next-Generation Sequencing. J Clin Oncol (2018) 36(7):633-41. doi: 10.1200/JCO.2017.75.3384

36. Liu SV, Reck M, Mansfield AS, Mok T, Scherpereel A, Reinmuth N, et al. Updated Overall Survival and PD-L1 Subgroup Analysis of Patients With Extensive-Stage Small-Cell Lung Cancer Treated With Atezolizumab, Carboplatin, and Etoposide (Impower133). J Clin Oncol (2021) 39(6):61930. doi: $10.1200 /$ JCO.20.01055

37. Rudin CM, Awad MM, Navarro A, Gottfried M, Peters S, Csoszi T, et al. Pembrolizumab or Placebo Plus Etoposide and Platinum as First-Line Therapy for Extensive-Stage Small-Cell Lung Cancer: Randomized, Double-Blind, Phase III KEYNOTE-604 Study. J Clin Oncol (2020) 38 (21):2369-79. doi: 10.1200/JCO.20.00793

38. Torralvo J, Friedlaender A, Achard V, Addeo A. The Activity of Immune Checkpoint Inhibition in KRAS Mutated Non-Small Cell Lung Cancer: A Single Centre Experience. Cancer Genomics Proteomics (2019) 16(6):577-82. doi: $10.21873 /$ cgp. 20160

39. Skoulidis F, Goldberg ME, Greenawalt DM, Hellmann MD, Awad MM, Gainor JF, et al. STK11/LKB1 Mutations and PD-1 Inhibitor Resistance in KRAS-Mutant Lung Adenocarcinoma. Cancer Discov (2018) 8(7):822-35. doi: $10.1200 / J C O .20 .01055$

40. Shire NJ, Klein AB, Golozar A, Collins JM, Fraeman KH, Nordstrom BL, et al. STK11 (LKB1) Mutations in Metastatic NSCLC: Prognostic Value in the Real World. PloS One (2020) 15(9):e0238358. doi: 10.1371/ journal.pone. 0238358

41. Papillon-Cavanagh S, Doshi P, Dobrin R, Szustakowski J, Walsh AM. STK11 and KEAP1 Mutations as Prognostic Biomarkers in an Observational RealWorld Lung Adenocarcinoma Cohort. ESMO Open (2020) 5(2). doi: 10.1136/esmoopen-2020-000706

42. Gainor JF, Shaw AT, Sequist LV, Fu X, Azzoli CG, Piotrowska Z, et al. EGFR Mutations and ALK Rearrangements Are Associated With Low Response Rates to PD-1 Pathway Blockade in Non-Small Cell Lung Cancer: A Retrospective Analysis. Clin Cancer Res (2016) 22(18):4585-93. doi: 10.1158/1078-0432.CCR-15-3101

43. Mazieres J, Drilon A, Lusque A, Mhanna L, Cortot AB, Mezquita L, et al. Immune Checkpoint Inhibitors for Patients With Advanced Lung Cancer and Oncogenic Driver Alterations: Results From the IMMUNOTARGET Registry. Ann Oncol (2019) 30(8):1321-8. doi: 10.1093/annonc/mdz167

44. Garassino MC, Cho BC, Kim JH, Mazieres J, Vansteenkiste J, Lena H, et al. Durvalumab as Third-Line or Later Treatment for Advanced Non-Small- 
Cell Lung Cancer (ATLANTIC): An Open-Label, Single-Arm, Phase 2 Study. Lancet Oncol (2018) 19(4):521-36. doi: 10.1016/S1470-2045(18) 30144-X

45. Lee CK, Man J, Lord S, Cooper W, Links M, Gebski V, et al. Clinical and Molecular Characteristics Associated With Survival Among Patients Treated With Checkpoint Inhibitors for Advanced Non-Small Cell Lung Carcinoma: A Systematic Review and Meta-Analysis. JAMA Oncol (2018) 4(2):210-6. doi: 10.1001/jamaoncol.2017.4427

46. Mamdani H, Ahmed S, Armstrong S, Mok T, Jalal SI. Blood-Based Tumor Biomarkers in Lung Cancer for Detection and Treatment. Transl Lung Cancer Res (2017) 6(6):648-60. doi: 10.21037/tlcr.2017.09.03

47. Thompson JC, Carpenter EL, Silva BA, Rosenstein J, Chien AL, Quinn K, et al. Serial Monitoring of Circulating Tumor DNA by Next-Generation Gene Sequencing as a Biomarker of Response and Survival in Patients With Advanced NSCLC Receiving Pembrolizumab-Based Therapy. JCO Precis Oncol (2021) 5. doi: 10.1200/PO.20.00321

48. Fares CM, Van Allen EM, Drake CG, Allison JP, Hu-Lieskovan S. Mechanisms of Resistance to Immune Checkpoint Blockade: Why Does Checkpoint Inhibitor Immunotherapy Not Work for All Patients? Am Soc Clin Oncol Educ Book (2019) 39:147-64. doi: 10.1200/EDBK_240837

49. Nicos M, Krawczyk P, Crosetto N, Milanowski J. The Role of Intratumor Heterogeneity in the Response of Metastatic Non-Small Cell Lung Cancer to Immune Checkpoint Inhibitors. Front Oncol (2020) 10:569202. doi: 10.3389/ fonc. 2020.569202

50. Saito Y, Horiuchi S, Morooka H, Ibi T, Takahashi N, Ikeya T, et al. InterTumor Heterogeneity of PD-L1 Expression in Non-Small Cell Lung Cancer. J Thorac Dis (2019) 11(12):4982-91. doi: 10.21037/jtd.2019.12.24

51. Suda K, Mitsudomi T. Inter-Tumor Heterogeneity of PD-L1 Status: Is It Important in Clinical Decision Making? J Thorac Dis (2020) 12(5):1770-5. doi: $10.21037 /$ jtd-20-1661

52. Gagne A, Wang E, Bastien N, Orain M, Desmeules P, Page S, et al. Impact of Specimen Characteristics on PD-L1 Testing in Non-Small Cell Lung Cancer: Validation of the IASLC PD-L1 Testing Recommendations. J Thorac Oncol (2019) 14(12):2062-70. doi: 10.1016/j.jtho.2019.08.2503

53. Ilie M, Long-Mira E, Bence C, Butori C, Lassalle S, Bouhlel L, et al. Comparative Study of the PD-L1 Status Between Surgically Resected Specimens and Matched Biopsies of NSCLC Patients Reveal Major Discordances: A Potential Issue for Anti-PD-L1 Therapeutic Strategies. Ann Oncol (2016) 27(1):147-53. doi: 10.1093/annonc/mdv489

54. Moutafi MK, Tao W, Huang R, Haberberger J, Alexander B, Ramkissoon S, et al. Comparison of Programmed Death-Ligand 1 Protein Expression Between Primary and Metastatic Lesions in Patients With Lung Cancer. J Immunother Cancer (2021) 9(4). doi: 10.1136/jitc-2020-002230

55. Munari E, Zamboni G, Lunardi G, Marconi M, Sommaggio M, Brunelli M, et al. PD-L1 Expression Comparison Between Primary and Relapsed NonSmall Cell Lung Carcinoma Using Whole Sections and Clone SP263. Oncotarget (2018) 9(54):30465-71. doi: 10.18632/oncotarget.25770

56. Hamilton G, Rath B. Immunotherapy for Small Cell Lung Cancer: Mechanisms of Resistance. Expert Opin Biol Ther (2019) 19(5):423-32. doi: 10.1080/14712598.2019.1592155

57. Chauvin JM, Zarour HM. TIGIT in Cancer Immunotherapy. J Immunother Cancer (2020) 8(2). doi: 10.1136/jitc-2020-000957

58. Zhang Q, Bi J, Zheng X, Chen Y, Wang H, Wu W, et al. Blockade of the Checkpoint Receptor TIGIT Prevents NK Cell Exhaustion and Elicits Potent Anti-Tumor Immunity. Nat Immunol (2018) 19(7):723-32. doi: 10.1038/ s41590-018-0132-0

59. Johnston RJ, Comps-Agrar L, Hackney J, Yu X, Huseni M, Yang Y, et al. The Immunoreceptor TIGIT Regulates Antitumor and Antiviral CD8(+) T Cell Effector Function. Cancer Cell (2014) 26(6):923-37. doi: 10.1016/ j.ccell.2014.10.018

60. Rodriguez-Abreu D, Johnson ML, Hussein MA, Cobo M, Patel AJ, Secen NM, et al. Primary Analysis of a Randomized, Double-Blind, Phase II Study of the AntiTIGIT Antibody Tiragolumab (Tira) Plus Atezolizumab (Atezo) Versus Placebo Plus Atezo as First-Line (1L) Treatment in Patients With PD-L1-Selected NSCLC (CITYSCAPE). ASCO 2020 Annual Meeting, Virtual platform 38. (2020). pp. 9503-.

61. Niu J, Maurice-Dror C, Lee DH, Kim DW, Nagrial A, Voskoboynik M, et al. First-in-Human Phase 1 Study of the Anti-TIGIT Antibody Vibostolimab as
Monotherapy or With Pembrolizumab for Advanced Solid Tumors, Including Non-Small-Cell Lung Cancer. Ann Oncol (2021) 33(2):169-80. doi: 10.1016/j.annonc.2021.11.002

62. Qin S, Xu L, Yi M, Yu S, Wu K, Luo S. Novel Immune Checkpoint Targets: Moving Beyond PD-1 and CTLA-4. Mol Cancer (2019) 18(1):155. doi: 10.1186/s12943-019-1091-2

63. Lipson EJ, Tawbi HA-H, Schadendorf D, Ascierto PA, Matamala L, Gutiérrez EC, et al. Relatlimab (RELA) Plus Nivolumab (NIVO) Versus NIVO in First-Line Advanced Melanoma: Primary Phase III Results From RELATIVITY-047 (CA224-047). ASCO 2020 Annual Meeting, Virtual platform 39. (2021). pp. 9503-.

64. Anderson AC. Tim-3, a Negative Regulator of Anti-Tumor Immunity. Curr Opin Immunol (2012) 24(2):213-6. doi: 10.1016/j.coi.2011.12.005

65. Zhang Y, Cai P, Liang T, Wang L, Hu L. TIM-3 Is a Potential Prognostic Marker for Patients With Solid Tumors: A Systematic Review and MetaAnalysis. Oncotarget (2017) 8(19):31705-13. doi: 10.18632/oncotarget.15954

66. Hahn AW, Gill DM, Pal SK, Agarwal N. The Future of Immune Checkpoint Cancer Therapy After PD-1 and CTLA-4. Immunotherapy (2017) 9(8):68192. doi: $10.2217 /$ imt-2017-0024

67. Wolf Y, Anderson AC, Kuchroo VK. TIM3 Comes of Age as an Inhibitory Receptor. Nat Rev Immunol (2020) 20(3):173-85. doi: 10.1038/s41577-0190224-6

68. Haanen JB, Cerundolo V. NKG2A, a New Kid on the Immune Checkpoint Block. Cell (2018) 175(7):1720-2. doi: 10.1016/j.cell.2018.11.048

69. Kochan G, Escors D, Breckpot K, Guerrero-Setas D. Role of Non-Classical MHC Class I Molecules in Cancer Immunosuppression. Oncoimmunology (2013) 2(11):e26491. doi: 10.4161/onci.26491

70. Levy EM, Bianchini M, Von Euw EM, Barrio MM, Bravo AI, Furman D, et al. Human Leukocyte Antigen-E Protein Is Overexpressed in Primary Human Colorectal Cancer. Int J Oncol (2008) 32(3):633-41. doi: 10.3892/ ijo.32.3.633

71. A Martinez-Marti ed. COAST: An Open-Label, Phase 2, Multidrug Platform Study of Durvalumab Alone or in Combination With Novel Agents in Patients With Unresectable, Stage III NSCLC Vol. 2021. ESMO Congress. Abstract presented at ESMO 2021, virtual platform (2021).

72. Yu M, Guo G, Huang L, Deng L, Chang CS, Achyut BR, et al. CD73 on Cancer-Associated Fibroblasts Enhanced by the A2B-Mediated Feedforward Circuit Enforces an Immune Checkpoint. Nat Commun (2020) 11(1):515. doi: 10.1038/s41467-019-14060-x

73. Zhang B. CD73: A Novel Target for Cancer Immunotherapy. Cancer Res (2010) 70(16):6407-11. doi: 10.1158/0008-5472.CAN-10-1544

74. Leclerc BG, Charlebois R, Chouinard G, Allard B, Pommey S, Saad F, et al. CD73 Expression Is an Independent Prognostic Factor in Prostate Cancer. Clin Cancer Res (2016) 22(1):158-66. doi: 10.1158/1078-0432.CCR-15-1181

75. Turcotte M, Spring K, Pommey S, Chouinard G, Cousineau I, George J, et al. CD73 Is Associated With Poor Prognosis in High-Grade Serous Ovarian Cancer. Cancer Res (2015) 75(21):4494-503. doi: 10.1158/0008-5472.CAN14-3569

76. Allard B, Pommey S, Smyth MJ, Stagg J. Targeting CD73 Enhances the Antitumor Activity of Anti-PD-1 and Anti-CTLA-4 Mabs. Clin Cancer Res (2013) 19(20):5626-35. doi: 10.1158/1078-0432.CCR-13-0545

77. Hay CM, Sult E, Huang Q, Mulgrew K, Fuhrmann SR, McGlinchey KA, et al. Targeting CD73 in the Tumor Microenvironment With MEDI9447. Oncoimmunology (2016) 5(8):e1208875. doi: 10.1080/2162402X.2016.1208875

78. Martinez-Marti A. COAST: An Open-Label, Randomised, Phase II Platform Study of Durvalumab Alone or in Combination With Novel Agents in Patients With Locally Advanced, Unresectable, Stage III NSCLC. ESMO Congress. Abstract presented at ESMO 2021, virtual platform (2021).

79. Azghadi S, Daly ME. Radiation and Immunotherapy Combinations in NonSmall Cell Lung Cancer. Cancer Treat Res Commun (2021) 26:100298. doi: 10.1016/j.ctarc.2020.100298

80. Jabbour SK, Lee KH, Frost N, Breder V, Kowalski DM, Pollock T, et al. Pembrolizumab Plus Concurrent Chemoradiation Therapy in Patients With Unresectable, Locally Advanced, Stage III Non-Small Cell Lung Cancer: The Phase 2 KEYNOTE-799 Nonrandomized Trial. JAMA Oncol (2021) 7(9):19. doi: 10.1001/jamaoncol.2021.2301

81. Huang Q, Zhang H, Hai J, Socinski MA, Lim E, Chen H, et al. Impact of PD-L1 Expression, Driver Mutations and Clinical Characteristics on Survival After 
Anti-PD-1/PD-L1 Immunotherapy Versus Chemotherapy in Non-Small-Cell Lung Cancer: A Meta-Analysis of Randomized Trials. Oncoimmunology (2018) 7(12):e1396403. doi: 10.1080/2162402X.2017.1396403

82. Calles A, Riess JW, Brahmer JR. Checkpoint Blockade in Lung Cancer With Driver Mutation: Choose the Road Wisely. Am Soc Clin Oncol Educ Book (2020) 40:372-84. doi: 10.1200/EDBK_280795

83. Canon J, Rex K, Saiki AY, Mohr C, Cooke K, Bagal D, et al. The Clinical KRAS(G12C) Inhibitor AMG 510 Drives Anti-Tumour Immunity. Nature (2019) 575(7781):217-23. doi: 10.1038/s41586-019-1694-1

84. Sen T, Gay CM, Byers LA. Targeting DNA Damage Repair in Small Cell Lung Cancer and the Biomarker Landscape. Transl Lung Cancer Res (2018) 7 (1):50-68. doi: $10.21037 / \mathrm{tlcr} .2018 .02 .03$

85. Yamaguchi NH. Smoking, Immunity, and DNA Damage. Transl Lung Cancer Res (2019) 8(Suppl 1):S3-6. doi: 10.21037/tlcr.2019.03.02

86. Fontes FL, Pinheiro DM, Oliveira AH, Oliveira RK, Lajus TB, Agnez-Lima LF. Role of DNA Repair in Host Immune Response and Inflammation. Mutat Res Rev Mutat Res (2015) 763:246-57. doi: 10.1016/j.mrrev.2014.11.004

87. Bednarski JJ, Sleckman BP. At the Intersection of DNA Damage and Immune Responses. Nat Rev Immunol (2019) 19(4):231-42. doi: 10.1038/ s41577-019-0135-6

88. Zhang J, Shih DJH, Lin SY. Role of DNA Repair Defects in Predicting Immunotherapy Response. biomark Res (2020) 8:23. doi: 10.1186/s40364020-00202-7

89. Teo MY, Seier K, Ostrovnaya I, Regazzi AM, Kania BE, Moran MM, et al. Alterations in DNA Damage Response and Repair Genes as Potential Marker of Clinical Benefit From PD-1/PD-L1 Blockade in Advanced Urothelial Cancers. J Clin Oncol (2018) 36(17):1685-94. doi: 10.1200/JCO.2017.75.7740

90. Strickland KC, Howitt BE, Shukla SA, Rodig S, Ritterhouse LL, Liu JF, et al. Association and Prognostic Significance of BRCA1/2-Mutation Status With Neoantigen Load, Number of Tumor-Infiltrating Lymphocytes and Expression of PD-1/PD-L1 in High Grade Serous Ovarian Cancer. Oncotarget (2016) 7(12):13587-98. doi: 10.18632/oncotarget.7277

91. Ricciuti B, Recondo G, Spurr LF, Li YY, Lamberti G, Venkatraman D, et al. Impact of DNA Damage Response and Repair (DDR) Gene Mutations on Efficacy of PD-(L)1 Immune Checkpoint Inhibition in Non-Small Cell Lung Cancer. Clin Cancer Res (2020) 26(15):4135-42. doi: 10.1158/10780432.CCR-19-3529

92. Marcus L, Lemery SJ, Keegan P, Pazdur R. FDA Approval Summary: Pembrolizumab for the Treatment of Microsatellite Instability-High Solid Tumors. Clin Cancer Res (2019) 25(13):3753-8. doi: 10.1158/1078-0432.CCR$18-4070$

93. van Gool IC, Eggink FA, Freeman-Mills L, Stelloo E, Marchi E, de Bruyn M, et al. POLE Proofreading Mutations Elicit an Antitumor Immune Response in Endometrial Cancer. Clin Cancer Res (2015) 21(14):3347-55. doi: 10.1158/1078-0432.CCR-15-0057

94. Telli ML, Chu C, Badve SS, Vinayak S, Silver DP, Isakoff SJ, et al. Association of Tumor-Infiltrating Lymphocytes With Homologous Recombination Deficiency and BRCA1/2 Status in Patients With Early Triple-Negative Breast Cancer: A Pooled Analysis. Clin Cancer Res (2020) 26(11):2704-10. doi: 10.1158/1078-0432.CCR-19-0664

95. Mamdani H, Chen J, Kim S, Ibrahim Y, Asad MFB, Nieva JJ, et al. DNA Damage Response and Repair (DDR) Gene Mutations and Correlation With Tumor Mutation Burden (TMB) in Non-Small Cell Lung Cancer (NSCLC). Chicago, IL: ASCO 2020 Annual Meeting 37. (2019). pp. 9100-.

96. Motwani M, Pesiridis S, Fitzgerald KA. DNA Sensing by the Cgas-STING Pathway in Health and Disease. Nat Rev Genet (2019) 20(11):657-74. doi: 10.1038/s41576-019-0151-1

97. Jiao S, Xia W, Yamaguchi H, Wei Y, Chen MK, Hsu JM, et al. PARP Inhibitor Upregulates PD-L1 Expression and Enhances Cancer-Associated Immunosuppression. Clin Cancer Res (2017) 23(14):3711-20. doi: 10.1158/ 1078-0432.CCR-16-3215

98. Kim ST, Smith SA, Mortimer P, Loembe AB, Cho H, Kim KM, et al. Phase I Study of Ceralasertib (AZD6738), A Novel DNA Damage Repair Agent, in Combination With Weekly Paclitaxel in Refractory Cancer. Clin Cancer Res (2021) 27(17):4700-9. doi: 10.1158/1078-0432.CCR-21-0251

99. Zhong S, Cui Y, Liu Q, Chen S. CAR-T Cell Therapy for Lung Cancer: A Promising But Challenging Future. J Thorac Dis (2020) 12(8):4516-21. doi: $10.21037 /$ jtd.2020.03.118
100. Lupo KB, Matosevic S. Natural Killer Cells as Allogeneic Effectors in Adoptive Cancer Immunotherapy. Cancers (Basel) (2019) 11(6). doi: 10.3390/cancers 11060769

101. Chen X, Amar N, Zhu Y, Wang C, Xia C, Yang X, et al. Combined DLL3Targeted Bispecific Antibody With PD-1 Inhibition Is Efficient to Suppress Small Cell Lung Cancer Growth. J Immunother Cancer (2020) 8(1). doi: 10.1136/jitc-2020-000785

102. Feng K, Guo Y, Dai H, Wang Y, Li X, Jia H, et al. Chimeric Antigen Receptor-Modified T Cells for the Immunotherapy of Patients With EGFRExpressing Advanced Relapsed/Refractory Non-Small Cell Lung Cancer. Sci China Life Sci (2016) 59(5):468-79. doi: 10.1007/s11427-016-5023-8

103. Hu Z, Zheng X, Jiao D, Zhou Y, Sun R, Wang B, et al. Lunx-CAR T Cells as a Targeted Therapy for Non-Small Cell Lung Cancer. Mol Ther Oncolytics (2020) 17:361-70. doi: 10.1016/j.omto.2020.04.008

104. Jie Y, Liu G, Feng L, Li Y, Mingyan E, Wu L, et al. PTK7-Targeting CAR TCells for the Treatment of Lung Cancer and Other Malignancies. Front Immunol (2021) 12:665970. doi: 10.3389/fimmu.2021.665970

105. Morgan RA, Yang JC, Kitano M, Dudley ME, Laurencot CM, Rosenberg SA. Case Report of a Serious Adverse Event Following the Administration of T Cells Transduced With a Chimeric Antigen Receptor Recognizing ERBB2. Mol Ther (2010) 18(4):843-51. doi: 10.1038/mt.2010.24

106. Thistlethwaite FC, Gilham DE, Guest RD, Rothwell DG, Pillai M, Burt DJ, et al. The Clinical Efficacy of First-Generation Carcinoembryonic Antigen (CEACAM5)-Specific CAR T Cells Is Limited by Poor Persistence and Transient Pre-Conditioning-Dependent Respiratory Toxicity. Cancer Immunol Immunother (2017) 66(11):1425-36. doi: 10.1007/s00262-017-2034-7

107. Rafiq S, Hackett CS, Brentjens RJ. Engineering Strategies to Overcome the Current Roadblocks in CAR T Cell Therapy. Nat Rev Clin Oncol (2020) 17 (3):147-67. doi: 10.1038/s41571-019-0297-y

108. Hyrenius-Wittsten A, Su Y, Park M, Garcia JM, Alavi J, Perry N, et al. Synnotch CAR Circuits Enhance Solid Tumor Recognition and Promote Persistent Antitumor Activity in Mouse Models. Sci Transl Med (2021) 13 (591). doi: 10.1126/scitranslmed.abd8836

109. Suarez ER, Chang de K, Sun J, Sui J, Freeman GJ, Signoretti S, et al. Chimeric Antigen Receptor T Cells Secreting Anti-PD-L1 Antibodies More Effectively Regress Renal Cell Carcinoma in a Humanized Mouse Model. Oncotarget (2016) 7(23):34341-55. doi: 10.18632/oncotarget.9114

110. Salmon H, Franciszkiewicz K, Damotte D, Dieu-Nosjean MC, Validire P, Trautmann A, et al. Matrix Architecture Defines the Preferential Localization and Migration of $\mathrm{T}$ Cells Into the Stroma of Human Lung Tumors. J Clin Invest (2012) 122(3):899-910. doi: 10.1172/JCI45817

111. Poorebrahim M, Melief J, Pico de Coana Y, LW S, Cid-Arregui A, Kiessling R. Counteracting CAR T Cell Dysfunction. Oncogene (2021) 40(2):421-35. doi: 10.1038/s41388-020-01501-x

112. Ren J, Zhang X, Liu X, Fang C, Jiang S, June CH, et al. A Versatile System for Rapid Multiplex Genome-Edited CAR T Cell Generation. Oncotarget (2017) 8(10):17002-11. doi: 10.18632/oncotarget.15218

113. Wang J, Lupo KB, Chambers AM, Matosevic S. Purinergic Targeting Enhances Immunotherapy of CD73(+) Solid Tumors With PiggybacEngineered Chimeric Antigen Receptor Natural Killer Cells. J Immunother Cancer (2018) 6(1):136. doi: 10.1186/s40425-018-0441-8

114. Brudno JN, Kochenderfer JN. Recent Advances in CAR T-Cell Toxicity: Mechanisms, Manifestations and Management. Blood Rev (2019) 34:45-55. doi: 10.1016/j.blre.2018.11.002

Conflict of Interest: The authors have following conflicts of interest within the past 2 years, none of which influenced the work being submitted. HM: Advisory role - Zentalis. GD: Research grant - BMS, AstraZeneca, Merck; Honoraria AstraZeneca, Curio Science. SJ: Research grant - AstraZeneca, Astex, Tesaro; Consultant - Adaptimmune.

The remaining authors declare that the research was conducted in the absence of any commercial or financial relationships that could be construed as a potential conflict of interest.

Publisher's Note: All claims expressed in this article are solely those of the authors and do not necessarily represent those of their affiliated organizations, or those of the publisher, the editors and the reviewers. Any product that may be evaluated in 
this article, or claim that may be made by its manufacturer, is not guaranteed or endorsed by the publisher.

Copyright $\odot 2022$ Mamdani, Matosevic, Khalid, Durm and Jalal. This is an openaccess article distributed under the terms of the Creative Commons Attribution
License (CC BY). The use, distribution or reproduction in other forums is permitted, provided the original author(s) and the copyright owner(s) are credited and that the original publication in this journal is cited, in accordance with accepted academic practice. No use, distribution or reproduction is permitted which does not comply with these terms. 